\title{
Comment on:"Precipitating factors and maternal and neonatal outcomes of heart failure in pregnancy: a retrospective analysis in a large tertiary hospital in China, 2012-2017"
}

\author{
Özge Turgay Yıldırım ${ }^{1}$ • Özge Senem Yücel Çiçek ${ }^{2}$
}

Received: 12 November 2019 / Accepted: 26 February 2020 / Published online: 9 March 2020

(c) Springer-Verlag GmbH Germany, part of Springer Nature 2020

We read with great interest the article by Chen et al. [1] entitled "Precipitating factors and maternal and neonatal outcomes of heart failure in pregnancy: a retrospective analysis in a large tertiary hospital in China, 2012-2017”. Although this is a well-designed study, we would like to address some points that merit more attention.

Pregnancy-associated heart failure is a rare but very serious problem which may cause severe complications in pregnancy [2]. Left ventricular ejection fraction is a very important parameter at pregnant heart failure patients. Previous studies show that heart failure with preserved ejection fraction is a major problem in older population but appears to be less dangerous and cause no major clinical effect in pregnancy [3]. Chen et al. [1] states that ejection fraction of the study population was $55.40 \pm 4.54$. Even though mean ejection fraction value is high, the patients show pregnancyspecific disorders such as preeclampsia and non-pregnancyspecific conditions such as lung infections and cardiac problems. These results show the clinicians that they must still be careful despite the high ejection fraction values. We should treat heart failure according to the patient's clinic, not numerical values.

At congenital heart disease patients, the impact of pregnancy and effects on long-term outcome is not well studied and not clear. These patients should be evaluated before pregnancy and risk assessment should be made [3]. In this paper, we saw that all maternal deaths are patients

This comment refers to the article available online at https://doi. org/10.1007/s00404-019-05350-2.

Özge Turgay Yıldırım

ozgeturgay@gmail.com

1 Department of Cardiology, Eskisehir City Hospital, Odunpazarı, Eskisehir, Turkey

2 Department of Obstetrics and Gynecology, Kocaeli University Faculty of Medicine, Kocaeli, Turkey with various congenital heart conditions and Eisenmenger syndrome which shows the importance of this disorder [1]. Suspected congenital heart disease patients need immediate attention before and during pregnancy and must be treated in specialized centers by a multidisciplinary heart team [3].

Author contribution ÖTY, ÖSYÇ: project development, manuscript writing.

\section{Compliance with ethical standards}

Conflict of interest The authors declare that they have no conflict of interest.

\section{References}

1. Chen H, Wang X, Yu H (2019) Precipitating factors and maternal and neonatal outcomes of heart failure in pregnancy: a retrospective analysis in a large tertiary hospital in China, 2012-2017. Arch Gynecol Obstet. https://doi.org/10.1007/s00404-019-05350-2

2. Sliwa K, Hilfiker-Kleiner D, Petrie MC, Mebazaa A, Pieske B, Buchmann E et al (2010) Current state of knowledge on aetiology, diagnosis, management, and therapyof peripartum cardiomyopathy. Eur J Heart Fail 12:767-778

3. Regitz-Zagrosek V, Roos-Hesselink JW, Bauersachs J, Blomström-Lundqvist C, Cífková R, De Bonis M et al (2018) 2018 ESC Guidelines for the management of cardiovascular diseases during pregnancy. Eur Heart J 39(34):3165-3241. https://doi. org/10.1093/eurheartj/ehy340

Publisher's Note Springer Nature remains neutral with regard to jurisdictional claims in published maps and institutional affiliations. 